\title{
Standalone oblique lateral interbody fusion vs. combined with percutaneous pedicle screw in spondylolisthesis
}

Wei $\mathrm{He}^{1 \dagger}$, Da He $\mathrm{H}^{1 \dagger}$, Yuqing Sun ${ }^{1}$, Yonggang Xing ${ }^{1}$, Jiankun Wen², Weiheng Wang${ }^{2}$, Yanhai Xi ${ }^{2}$, Mingming Liu', Wei $\operatorname{Tian}^{1^{*}}$ and Xiaojian Ye $\mathrm{2}^{2^{*}}$

\begin{abstract}
Background: To compare standalone oblique lateral interbody fusion (OLIF) vs. OLIF combined with posterior bilateral percutaneous pedicle screw fixation (OLIF combined) for the treatment of lumbar spondylolisthesis.

Methods: This was a retrospective study of patients who underwent standalone OLIF or combined OLIF between 07/2014 and 08/2017 at two hospitals in China. Direct decompressions were not performed. Visual analog scale (VAS), Oswestry Disability Index (ODI), satisfaction rate, anterior/posterior disc heights (DH), foraminal height (FH), foraminal width (FW), cage subsidence, cage retropulsion, fusion rate, and complications were analyzed. All imaging examinations were read independently by two physicians and the mean measurements were used for analysis.

Results: A total of 73 patients were included: 32 with standalone OLIF and 41 with combined OLIF. The total complication rate was $25.0 \%$ with standalone OLIF and $26.8 \%$ with combined OLIF. There were no differences in VAS and ODI scores by 2 years of follow-up, but the scores were better with standalone OLIF at 1 week and 3 months $(P<0.05)$. PDH and FW was smaller in the combined OLIF group compared with the standalone OLIF group before and after surgery (all $P<0.05$ ). There were significant differences in FH before surgery and at 1 week and 3 months between the two groups (all $P<0.05)$, but the difference disappeared by 2 years $(P=0.111)$. Cage subsidence occurred in $7.3 \%$ (3/41) and $7.3 \%(3 / 41)$ of the patients at 3 and 24 months, respectively, in the combined OLIF group, compared with $6.3 \%$ (2/32) and 15.6\% (5/32), respectively, in the standalone OLIF group at the same time points $(P=0.287)$. There was no cage retropulsion in both groups at 2 years. The fusion rate was $85.4 \%(35 / 41)$ in the combined OLIF group and $84.4 \%(27 / 32)$ in the standalone OLIF group at 3 months $(P=0.669)$. At 24 months, the fusion rate was $100.0 \%$ in the combined OLIF group and $93.8 \%$ (30/32) in the standalone OLIF group $(P=0.066)$.

\footnotetext{
* Correspondence: tianwei victor@163.com; xjyespine@smmu.edu.cn

'Wei He and Da He contributed equally to this work.

'Department of Spine Surgery, Beijing Jishuitan Hospital, No.31 Xinjiekou East

Street, Xicheng District, Beijing 100035, China

2Department of Spine Surgery, Shanghai Changzheng Hospital, No.415,

Fengyang road, Huangpu District, Shanghai 200003, China
}

(c) The Author(s). 2020 Open Access This article is licensed under a Creative Commons Attribution 4.0 International License, which permits use, sharing, adaptation, distribution and reproduction in any medium or format, as long as you give appropriate credit to the original author(s) and the source, provide a link to the Creative Commons licence, and indicate if changes were made. The images or other third party material in this article are included in the article's Creative Commons. licence, unless indicated otherwise in a credit line to the material. If material is not included in the article's Creative Commons licence and your intended use is not permitted by statutory regulation or exceeds the permitted use, you will need to obtain permission directly from the copyright holder. To view a copy of this licence, visit http://creativecommons.org/licenses/by/4.0/ The Creative Commons Public Domain Dedication waiver (http://creativecommons.org/publicdomain/zero/1.0/) applies to the data made available in this article, unless otherwise stated in a credit line to the data. 
(Continued from previous page)

Conclusion: Standalone OLIF may achieve equivalent clinical and radiological outcomes than OLIF combined with fixation for spondylolisthesis. The rate of complications was similar between the two groups. Patients who are osteoporotic might be better undergoing combined rather than standalone OLIF. The possibilty of proof lies within a future prospective study, preferably an RCT.

Keywords: Spondylolisthesis, Oblique lumbar interbody fusion, Percutaneous pedicle screw fixation, Radiological outcomes

\section{Background}

Degenerative lumbar spine disease (DSD) is an important cause of disability, affecting $3.6 \%$ of the world population. The prevalence of DSD is four times higher in low-and middle-income countries compared with highincome countries [1].

Fusionis the corners to neither treatment of an unstable degenerative lumbar spinal disease, but various techniques are available [2, 3]. Oblique lateral interbody fusion (OLIF) is are gently introduced surgical technique [4] that evolved from lateral lumbar interbody fusion (LLIF) and anterior lumbar interbody fusion (ALIF) [5]. To avoid femoral nerve plexus injury during the transpsoas approach in LLIF, OLIF use a natural space between the left lateral border of the abdominal aorta (AA) and the anterior medial border of the left psoas muscle (PM), all owing access to the lesion discs from L2/3 to L4/5 without splitting the left PM [6]. OLIF has advantages over LLIF in that the larger lateral cage can achieve greater fusion rate and angular correction. This surgical procedure alleviate spost operative back pain, shortens the time of operation and hospitalization, and also reduces bleeding compared with open surgery $[5,6]$.

It remains controversial as whether internal fixation is required for OLIF [7]. The standalone OLIF approach is associated with small trauma and short operation time and hospital stay [8-11]. Zeng et al. [7] suggested that the rate of complications was lower with the use of combined screw fixation. Posterior pedicle screw fixation can be indicated inpatients with endplate damage [7]. Ohtori et al. [12] used posterior screws in all their patients and reported good outcomes. Studies comparing standalone OLIF and OLIF combined with pedicle screws are lacking inpatients with spondylolisthesis.

Considering the emerging interest for OLIF, the present study aimed to analyze the clinical experience with standalone OLIF and OLIF combined with pedicle screws, and to compare their clinical and radiological outcomes in the management of primary spondylolisthesis.

\section{Materials and method}

\section{Study design and patients}

This was a retrospective study of patients who underwent standalone OLIF or OLIF combined with posterior bilateral percutaneous pedicle screw fixation (combined OLIF group) between July 2014 and August 2017 at the Beijing Jishuitan Hospital (combined OLIF group) and the Shanghai Changzheng Hospital (standalone OLIF group). Only one type of procedure was performed at each hospital. The study was approved by the ethical committees of the Beijing Jishuitan Hospital (approval number: 201811-03) and the Shanghai Changzheng Hospital (approval number: 201812-01). The need for individual consent was waived by both committees because of the retrospective nature of the study.

Lumbar spondylolisthesis was diagnosed according to plain X-ray examination [13]. The inclusion criteria were: 1) patients who underwent surgery at the L4-5 level; 2) diagnosis of spondylolisthesis with symptoms; 3 ) grade I spondylolisthesis $(<25 \%)$ based on Meyerding classification; 4) failure to $>6$ months of conservative treatment; 5) no history of lumbar surgery at L4-5; and 6) $\geq 24$ months of follow-up. The exclusion criteria were: 1) lumbar spondylolysis; 2) lumbar canal stenosis; 3) lumbar disc herniation; or 4) incomplete medical records.

\section{Surgical techniques}

Surgeries were performed by chief physicians with $>20$ years of surgical experience in both hospitals. In the standalone OLIF group, surgery was performed based on standard procedure $[5,6]$. Presence of scoliosis did not affect the side of the surgical approach. A4-cm skin incision was made $6-10 \mathrm{~cm}$ anterior to the mid-portion of the marked disc. The surgeons approached the retroperitoneal space by blunt dissection and mobilization of the peritoneum anteriorly to expose the anatomical oblique lateral corridor, followed by intervertebral cage insertion (Clydesdale spinal system, Medtronic, Memphis, TN, USA; $12 \mathrm{~mm}$ in height $\times 50 \mathrm{~mm}$ in length $\times 18 \mathrm{~mm}$ in width, $6^{\circ}$ lordotic, $3.27 \mathrm{cc}$ graft volume) filled with demineralized bone matrix DBM (Wright Medical Technology Inc., Arlington, TN, USA). Direct decompressions were not performed.

In the combined OLIF group, OLIF surgery was performed based on the standard procedure $[5,6]$, as above. After fusion, the patients were placed in the prone position to undergo posterior bilateral percutaneous pedicle 
screw fixation (CD Horizon Solera Voyager Spinal System, Medtronic, Memphis, TN, USA). None of the patients in either group underwent additional laminectomy.

Non-steroidal drugs were used for postoperative analgesia with muscle relaxants. The back muscle function was exercised by swimming and agymnastic named "sky diver to superman to swimmer", as recommended by the North American Spine Society (NASS).

\section{Data collection}

The demographic data included sex, age, bone mineral density (BMD), and fixation level. BMD was measured by dual-energy X-ray absorptiometry (DEXA). The Tscore is the BMD when compared to the young normal reference mean. $\mathrm{T}<-2.5$ was defined as osteoporosis. The patients' clinical results were routinely assessed based on visual analog scores (VAS) for leg pain and the Oswestry disability index (ODI,version2.0) at 1 week, 3 months, and 24 months. The patients were surveyed for satisfaction: satisfied, unsatisfied, and feeling worse than before surgery. All patients underwent routine preoperative and postoperative standing anteroposterior (AP) /lateral plain X-ray, flexion-extension plain X-ray, and computed tomography (CT). Assessments were done for cage subsidence and cage retropulsion. As the true footprint of the cage can be determined on CT images, CT images were used to analyze the cage position. Cage subsidence was evaluated using postoperative and serial follow-up sagittal CT images, and was defined as a cage sinking into an adjacent vertebral body by $>2 \mathrm{~mm}$, based on comparisons with previous CT images [14]. Cage migration was defined as posterior movement of the cage by $\geq 3 \mathrm{~mm}$ compared with the immediate postoperative estate. These data were collected before surgery, and at 1 week, 3 months, and 2 years postoperatively. In addition, complications were recorded.
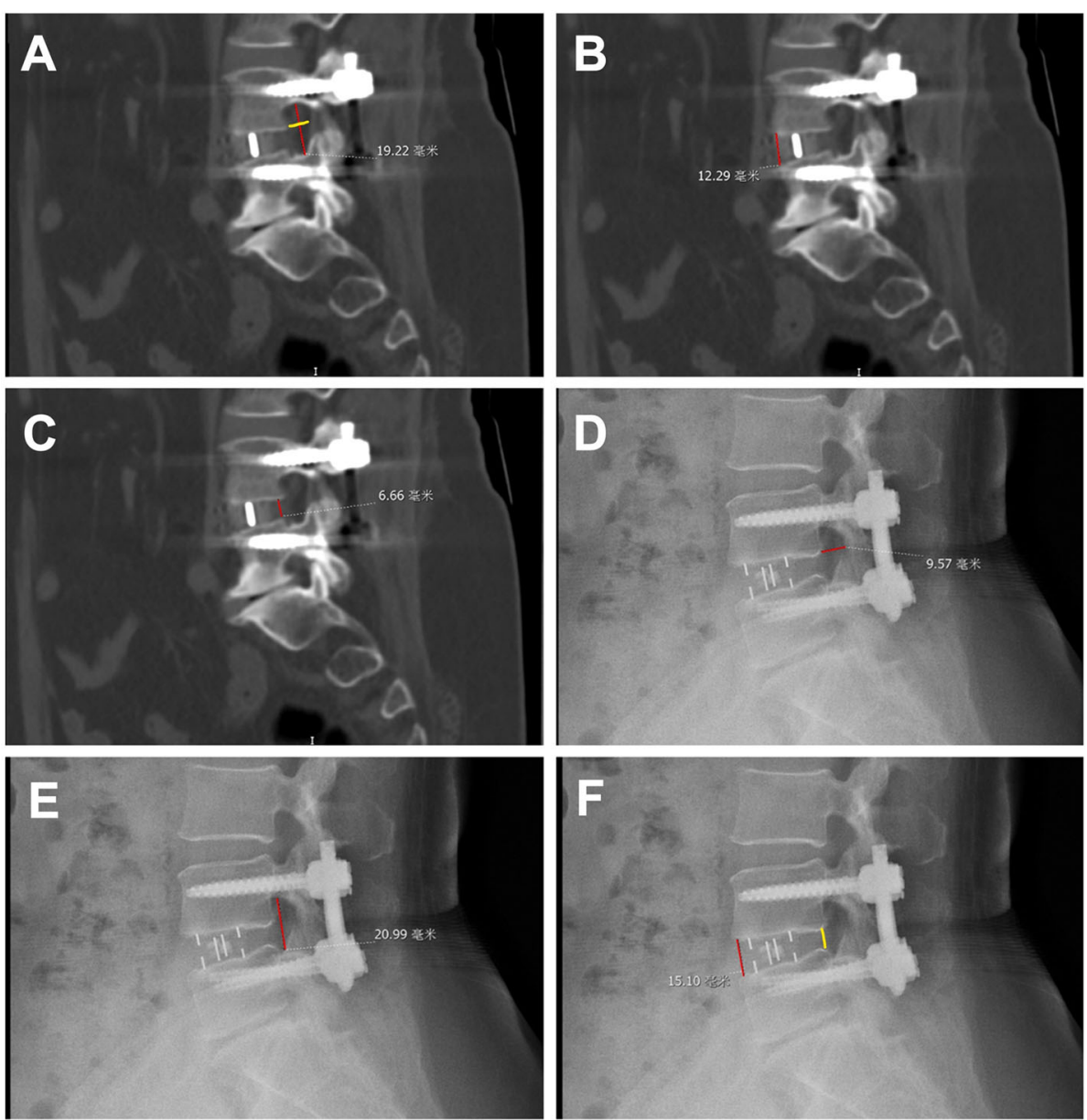

Fig. 1 Radiological measurements (CT and X ray) used in this study. a Sagittal computed tomography (CT) image of lumbar vertebrae. The red line shows the foraminal height $(F H)$. The yellow line shows the foraminal width (FW). b Sagittal CT image of lumbar vertebrae. The red line shows the anterior disc height (ADH), (c) Sagittal CT image of lumbar vertebrae. The red line shows the posterior disc height (PDH), (d) Lateral Xray image of lumbar vertebrae. The red line shows the FW. e Lateral X-ray image of lumbar vertebrae. The red line shows the FH. $\mathbf{f}$ Lateral X-ray image of lumbar vertebrae. The red line shows the ADH. The yellow line shows the PDH 


\section{Lumbar radiological measurements}

Figure 1 presents the radiological measurements. Radiological outcomes were measured on lateral X-rays and sagittal CT images, including anterior/posterior disc heights $(\mathrm{ADH} / \mathrm{PDH})$, foraminal height $(\mathrm{FH})$, foraminal width (FW), fusion rate, and cage subsidence. All imaging examinations were read independently by two physicians (at least 12 years of experience) who were blind to grouping and the mean measurements were used for analysis. The calculated intra-class correlation coefficients were all $>0.85$ for all variables. CT slice thickness was $2 \mathrm{~mm}$, as per routine practice. $\mathrm{ADH} / \mathrm{PDH}$ was defined as the distance at the anterior/posterior position from upper to lower endplate of the L4-5 level. FH was defined as the distance from the lower position of the pedicle of L4 to the upper position of the pedicle of L5. FW was defined as the distance from the lower posterior horn of the vertebral body of L4 to the vertex of the superior joint of L5. The fusion rate grading criteria were based on the Bridwell interbody fusion grading system [15]. Grades I and II were considered as successful.

\section{Statistic analysis}

Statistical analysis was performed using SPSS 18.0 for Windows (IBM, Armonk, NY, USA). Continuous data with normal distribution are presented as means \pm standard deviation, and were analyzed using the Student $\mathrm{t}$ test. Continuous data with non-normal distribution are presented as medians (range), and were analyzed using the Wilcoxon test. Categorical variables are presented as frequencies, and were analyzed using the Pearson chisquare test or the Fisher exact test, as appropriate. Twotailed $P$ values $<0.05$ were considered statistically significant.

\section{Results}

\section{Characteristics of the patients and clinical outcomes}

The characteristics of the patients are presented in Table 1. A total of 73 patients were included: 32 with standalone OLIF and 41 with combined OLIF.

Satisfaction with surgery was $87.5 \%$ with standalone OLIF and $92.7 \%$ with combined OLIF $(P=0.692)$. Patients in the standalone OLIF group had better ODI scores than

Table 1 Baseline and clinical data of the patients according to the surgical procedure they underwent

\begin{tabular}{llll}
\hline & OLIF+fixation & Standalone OLIF & $P$ \\
\hline $\mathrm{N}$ & 41 & 32 & \\
Sex & & & 0.679 \\
$\quad$ Male & $11(26.8 \%)$ & $10(31.3 \%)$ & \\
$\quad$ Female & $30(73.2 \%)$ & $22(68.7 \%)$ & 0.669 \\
Age (years) & $61.0 \pm 9.3$ & $59.8 \pm 13.7$ & 0.290 \\
Osteoporosis & $15(36.6 \%)$ & $8(25.0 \%)$ & \\
\hline
\end{tabular}

Table 2 Comparison of clinical outcomes between standalone and combined OLIF

\begin{tabular}{llll}
\hline & OLIF+fixation & Standalone OLIF & $P$ \\
\hline VAS (leg pain) & & & \\
Pre-op & $5.6 \pm 1.0$ & $5.8 \pm 0.7$ & 0.275 \\
Post-op 1 week & $3.2 \pm 0.8$ & $3.0 \pm 0.6$ & 0.228 \\
Post-op 3 months & $2.9 \pm 0.9$ & $1.5 \pm 0.7$ & $<0.001$ \\
Post-op 2 years & $2.2 \pm 0.5$ & $1.2 \pm 0.7$ & $<0.001$ \\
ODI & & & 0.342 \\
Pre-op & $44.8 \pm 3.3$ & $44.1 \pm 2.6$ & $<0.001$ \\
Post-op 1 week & $33.6 \pm 2.1$ & $30.9 \pm 2.0$ & $<0.001$ \\
Post-op 3 months & $20.7 \pm 2.6$ & $18.2 \pm 2.4$ & 0.716 \\
Post-op 2 years & $14.4 \pm 2.1$ & $14.6 \pm 1.8$ & 0.692 \\
Satisfaction & & & \\
Satisfied & $38(92.7 \%)$ & $28(87.5 \%)$ & \\
Unsatisfied & $3(7.3 \%)$ & $4(12.5 \%)$ &
\end{tabular}

$O D I$ Oswestry disability index, VAS visual analogue scale

patients in the combined OLIF group at 1 week $(30.9 \pm 2.0$ vs. $33.6 \pm 2.1, P<0.001)$ and 3 months $(18.2 \pm 2.4$ vs. $20.7 \pm 2.6, P<0.001)$, but there was no significant difference in ODI at 2 years $(14.6 \pm 1.8$ vs. $14.4 \pm 2.1, P=0.716)$. Patients in the standalone OLIF group suffered less leg pain at 3 months $(1.5 \pm 0.7$ vs. $2.9 \pm 0.9, P<0.001)$ and 2 years $(1.2 \pm 0.7$ vs. $2.2 \pm 0.5, P<0.001)$. The clinical outcomes are summarized in Table 2 and Figs. 2-3.

\section{Radiological outcomes}

There were no significant differences in ADH between the two groups during follow-up (all $P>0.05$ ). $\mathrm{PDH}$ and FW was smaller in the combined OLIF group compared with the standalone OLIF group before and after surgery

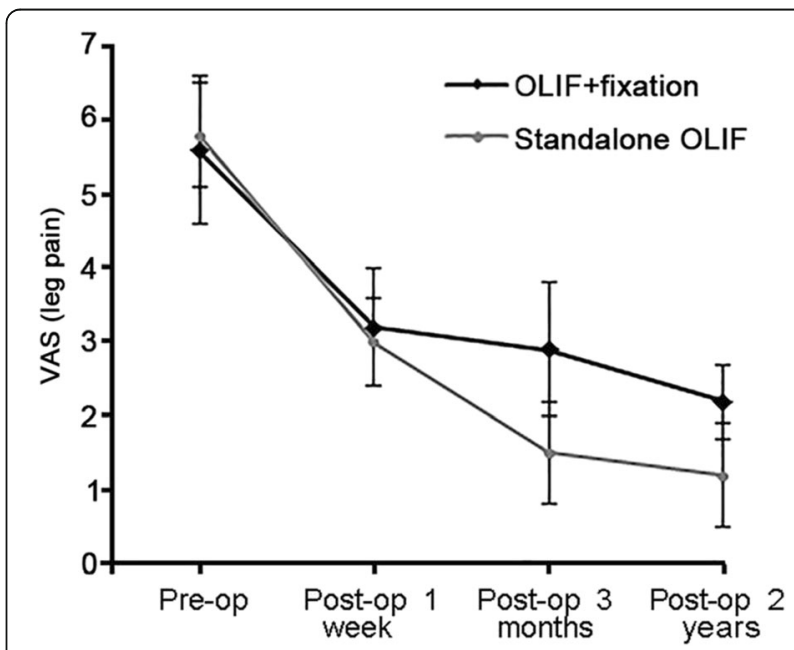

Fig. 2 Visual analogue scale of leg pain. Comparison between standalone oblique lateral interbody fusion (OLIF) and OLIF combined with pedicle screw fixation, from base line to 24 months after surgery 


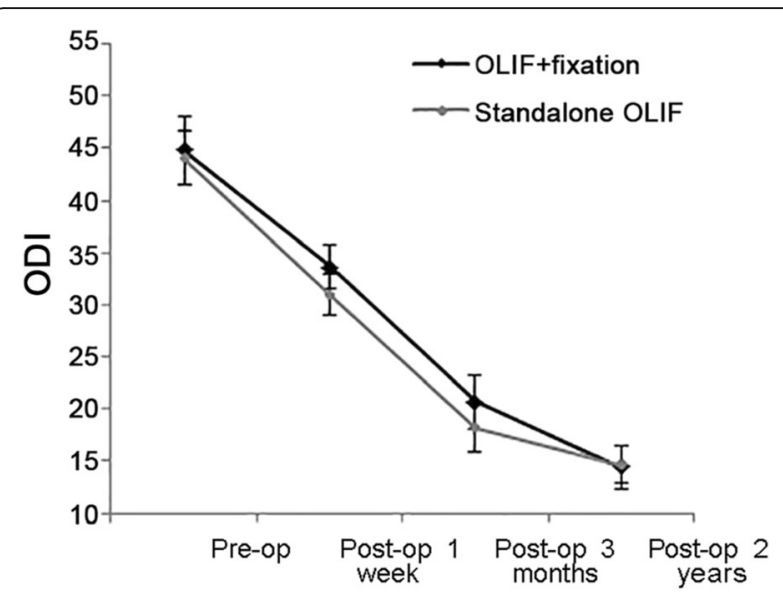

Fig. 3 Oswestry disability index. Comparison between standalone oblique lateral interbody fusion (OLIF) and OLIF combined with pedicle screw fixation, from base line to 24 months after surgery

(all $P<0.05$ ). There were significant differences in $\mathrm{FH}$ before surgery and at 1 week and 3 months between the two groups (all $P<0.05$ ), but the difference disappeared by 2 years $(P=0.111)$ (Table 3$)$.

Cage subsidence occurred in 7.3\% (3/41) and 7.3\% (3/41) of the patients at 3 and 24 months, respectively, in the combined OLIF group, compared with $6.3 \%(2 / 32)$ and $15.6 \%$ (5/32), respectively, in the standalone OLIF group at the same time points $(P=0.287)$. There was no cage retropulsion in both groups at 2 years.

The fusion rate was $85.4 \%(35 / 41)$ in the combined OLIF group and $84.4 \%(27 / 32)$ in the standalone OLIF group at 3 months $(P=0.669)$. At 24 months, the fusion rate was $100.0 \%$ in the combined OLIF group and $93.8 \%$ $(30 / 32)$ in the standalone OLIF group $(P=0.066)$.

\section{Complications}

The total complication rate was $26.8 \%(11 / 41)$ in the combined OLIF group and $25.0 \%(8 / 32)$ in standalone OLIF group (Table 4). In the combined OLIF group, five patients had transient sympathetic injury and leg numbness, but they needed no specific treatment and recovered spontaneously within 3 months. Three cases of L4 segmental artery injury were noticed intraoperatively and immediate hemostasis was achieved using a hemoclip. Three cases of L4/5 endplate injury were noticed intraoperatively (Fig. 4). In the standalone OLIF group, four patients(L4/5) complained of leg pain or numbness at 1 day after OLIF. Two cases of L4 segmental artery injury were noticed intraoperatively and immediate hemostasis was achieved using a hemoclip. Two cases of L4/5 endplate injury were noticed intraoperatively. None of the patients in either group had intraoperative dural tear, screw malposition, transient erebrospinal fluid leak,
Table 3 Comparison of radiological outcomes between standalone and combined OLIF

\begin{tabular}{|c|c|c|c|}
\hline & OLIF+fixation & Standalone OLIF & $P$ \\
\hline \multicolumn{4}{|l|}{$\overline{\mathrm{ADH}}$} \\
\hline Pre-op & $4.9 \pm 1.6$ & $6.8 \pm 2.5$ & $<0.001$ \\
\hline Post-op 1 week & $12.8 \pm 1.2$ & $12.7 \pm 0.7$ & 0.737 \\
\hline Post-op 3 months & $12.8 \pm 1.5$ & $12.6 \pm 0.5$ & 0.991 \\
\hline Post-op 2 years & $12.5 \pm 1.2$ & $12.0 \pm 0.4$ & 0.055 \\
\hline \multicolumn{4}{|l|}{$\mathrm{PDH}$} \\
\hline Pre-op & $4.1 \pm 2.0$ & $6.1 \pm 2.3$ & 0.010 \\
\hline Post-op 1 week & $8.7 \pm 1.7$ & $10.2 \pm 1.2$ & $<0.001$ \\
\hline Post-op 3 months & $8.6 \pm 1.7$ & $10.1 \pm 1.0$ & $<0.001$ \\
\hline Post-op 2 years & $8.3 \pm 1.6$ & $9.9 \pm 1.2$ & $<0.001$ \\
\hline \multicolumn{4}{|l|}{$\mathrm{FH}$} \\
\hline Pre-op & $12.7 \pm 3.7$ & $14.5 \pm 1.9$ & 0.009 \\
\hline Post-op 1 week & $16.6 \pm 4.0$ & $18.7 \pm 3.2$ & 0.014 \\
\hline Post-op 3 months & $16.6 \pm 4.0$ & $18.4 \pm 3.3$ & 0.032 \\
\hline Post-op 2 years & $16.4 \pm 3.9$ & $17.8 \pm 3.3$ & 0.111 \\
\hline \multicolumn{4}{|l|}{ FW } \\
\hline Pre-op & $7.4 \pm 2.3$ & $8.6 \pm 1.7$ & 0.017 \\
\hline Post-op 1 week & $9.6 \pm 1.5$ & $10.8 \pm 1.8$ & 0.018 \\
\hline Post-op 3 months & $9.4 \pm 2.2$ & $10.7 \pm 1.8$ & 0.011 \\
\hline Post-op 2 years & $9.4 \pm 2.2$ & $10.6 \pm 1.7$ & 0.016 \\
\hline Fusion rate at 3 months & & & 0.669 \\
\hline Gradel & 35 (85.4\%) & $27(84.4 \%)$ & \\
\hline Grade II & $4(9.8 \%)$ & $2(6.3 \%)$ & \\
\hline Grade III & $2(4.9 \%)$ & $3(9.4 \%)$ & \\
\hline Grade IV & 0 & 0 & \\
\hline Fusion rate at 2 years & & & 0.066 \\
\hline Grade I & $41(100.0 \%)$ & $30(93.8 \%)$ & \\
\hline Grade ॥ & 0 & $2(6.2 \%)$ & \\
\hline Grade III & 0 & 0 & \\
\hline Grade IV & 0 & 0 & \\
\hline
\end{tabular}

$\overline{A D H}$ anterior disc height, $P D H$ posterior disc height, $F H$ foraminal height, $F W$ foraminal width

Table 4 Complications after standalone and combined OLIF

\begin{tabular}{llll}
\hline & OLIF+fixation & Standalone OLIF & $P$ \\
\hline Intraoperative & & & \\
Segmental artery injury & $3(7.3 \%)$ & $2(6.3 \%)$ & 0.857 \\
$\quad$ Endplate damage & $3(7.3 \%)$ & $2(6.3 \%)$ & 0.857 \\
$\begin{array}{llll}\text { Post-operative } \\
\text { Leg weakness }\end{array}$ & $5(12.2 \%)$ & $4(12.5 \%)$ & 0.969 \\
Sympathetic chain injury & $5(12.2 \%)$ & $4(12.5 \%)$ & 0.969 \\
Cage subsidence & $3(7.3 \%)$ & $5(15.6 \%)$ & 0.287 \\
\hline
\end{tabular}




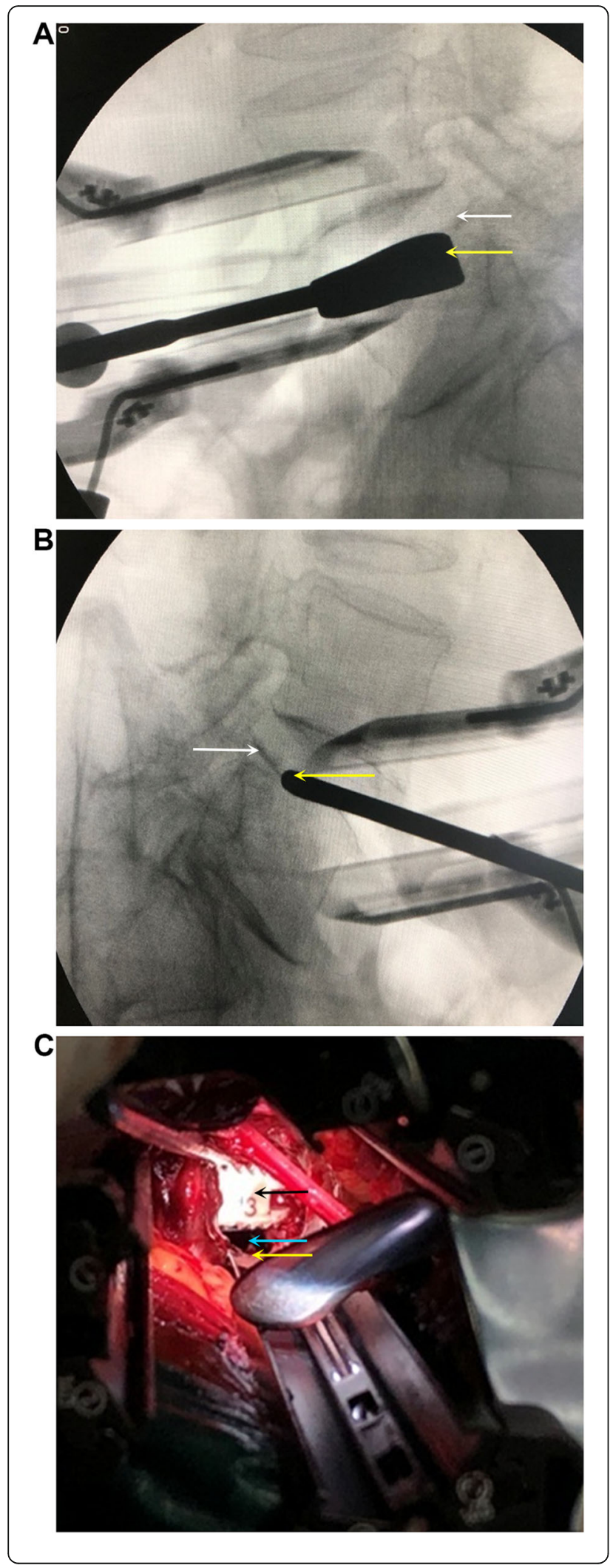

Fig. 4 Intraoperative endplate damage. a White arrow: normal superior endplate of L5. Yellow arrow: the trial mold breaks in the vertebral body. b White arrow: normal superior endplate of $L 5$. Yellow arrow: the trial mold breaks through the cortex of the endplate. c Yellow arrow: normal superior endplate of the vertebral body. Blue arrow: a cavity between the lower margin of the cage and the upper endplate of the vertebral body after the endplate is damaged and collapsed. The cavity was filled with DBM. White arrow: the cage

infection, adjacent segment disease, deep vein thrombosis, or cage retropulsion.

\section{Discussion}

OLIF has been found to result in a $30.2 \%$ median increase in the cross-sectional area of the dural sac [16] and a $30.0 \%$ average increase in the neural foramen area [17]. The results suggest that the standalone OLIF group achieved better clinical outcomes in the early postoperative term ( 1 week and 3 months), but the differences disappeared by 2 years. The probable reason is that standalone OLIF does not invade the muscle groups on both sides of the spine and does not cause intra muscular hematoma, leading to better early recovery [18]. The difference disappeared by 2 years once the muscles and hematoma healed in the combined OLIF group.

In the present study, the rate of cage subsidence in the standalone OLIF was $15.6 \%$ while it was $7.3 \%$ in the combined OLIF group. Zeng et al. [7] reported a rate of cage subsidence with standalone OLIF of 36.3\%, higher than in the combined OLIF group (29.9\%). Good clinical results of the OLIF without additional posterior pedicle screw fixation have been reported, but an indication was the absence of endplate damage [8-11]. Although the sample size was small in the present study, our results are supported by Zeng et al. [7] and the main reason for cage subsidence is probably endplate damage during surgery.

In total, there were three cases of cage subsidence in the standalone OLIF group and five in the combined OLIF group. All of them had a T score $<-2.5$ on DEXA. Standalone OLIF inpatients with mild lumbar spondylolisthesis could be associated with a concern about complications, especially cage subsidence. Based on the present study, a $\mathrm{T}$ score warning line of $<-2.5$ or body mass index (BMI) $\geq 30 \mathrm{~kg} / \mathrm{m}^{2}$ could be associated with worse outcomes of standalone OLIF [19]. Of course, cage subsidence may occur after OLIF combined with pedicle screw fixation as well, but theoretically pedicle screw fixation could add more protection. Patients who are osteoporotic or obese might be better undergoing combined rather than standalone OLIF. On the other hand, for patients without those risk factors, standalone OLIF could be enough. Formal analyses of $T$ values and BMI should be performed in future studies. In addition, the three patients with cage subsidence in the standalone 
OLIF group were elderly $(88,81$, and 77 years of age). Of course, osteoporosis is associated with age, and we cannot rule out which factor is more important based on three cases. Nevertheless, other authors reported similar results. Li et al. [20] and Lee et al. [21] showed that lower BMD could result in cage migration. Pan et al. [22] and Lee et al. [23] reported that BMI of patients with cage retropulsion was higher than that in those without. Future studies could examine whether additional posterior pedicle screw fixation could be applied in the operation.

Lin et al. [24] evaluated 52 patients who underwent standalone OLIF without posterior instrumentation and reported a fusion rate of $81.9 \%$ at $>12$ months after surgery when assessed by CT. Kim et al. [25] reported a 12month fusion rate of $92.9 \%$ in 29 OLIF patients with posterior pedicle screw fixation when assessed with $\mathrm{CT}$. In this study, we found that the low fusion rate in both OLIF group was related to cage subsidence, and the poor clinical effect was mostly inpatients who suffered from cage subsidence. The pedicle screw and the rod system are widely accepted and used to achieve stable and rigid fixation in patients undergoing fusion surgery, but there was no difference in fusion rate between the two groups, at least within 2 years of follow-up. The reason could be that despite the fact that standalone OLIF is more unstable compared with OLIF combined with screw implantation, the bilateral muscles remain intact with standalone OLIF, which could help stabilize the spine. Therefore, both methods achieved a similar fusion rate.

The results suggest that cage subsidence and adjacent vertebral fractures could be mutually causal. Endplate damage further causes trabecular bone fracture in the vertebral body, causing the vertebral body to be weakly supported, resulting in cage subsidence. Before calcification of vertebral hematoma, vertebral trabecular fracture and cage subsidence form a vicious circle. The intervertebral endplate and the cage are slightly moving, resulting in a decrease in the fusion rate (Fig. 5). Until the cancellous bone of the vertebral body is compressed to a certain density and reaches the support cage strength, a stable state is reached and the artificial bone in the cage ensures fusion when the growth of the upper and lower vertebral bodies starts. Micro-fractures in the vertebral body can produce hematoma, and the patient can feel pain and discomfort [18].

Despite the fact that fusion has been shown to achieve similar outcomes to those of conservative approaches [26], surgery was attempted in the patients included in the present study because those patients had failure to at least 6 months of conservative treatments. In addition, direct decompressions were not performed. Indeed, all patients included here suffered from grade I lumbar spondylolisthesis, and the instability of the lumbar spine

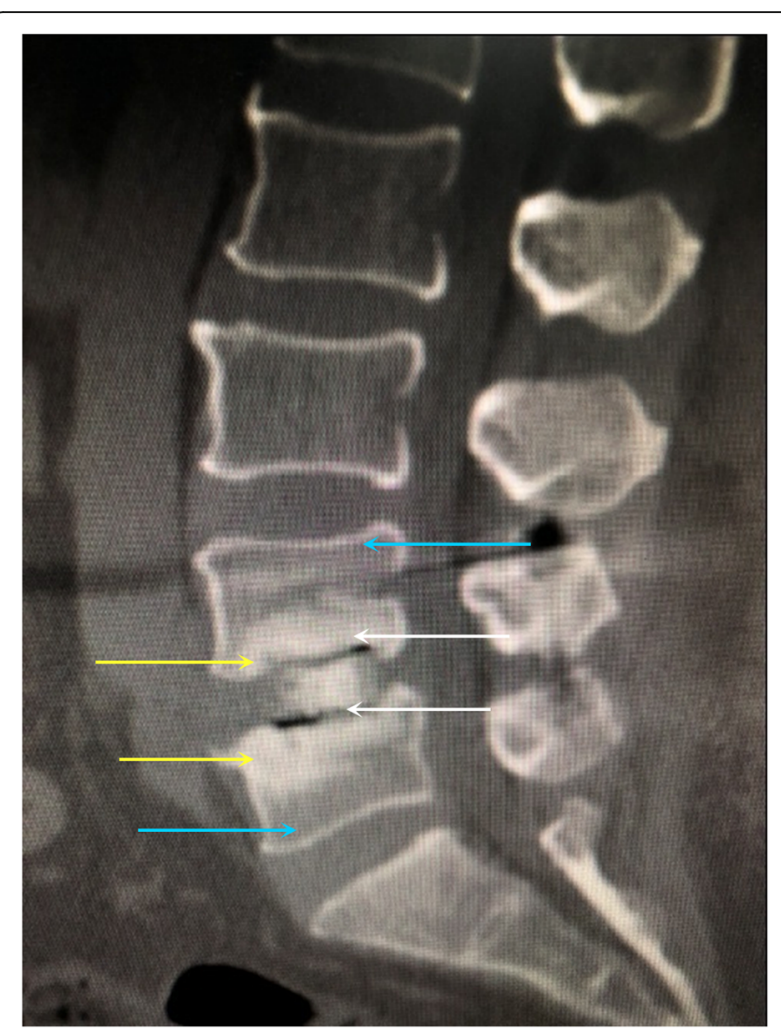

Fig. 5 Postoperative spine CT scan. There was potential translucency present at top and bottom of graft $(\llcorner 4 / 5$ cage). There were vertebral compression fractures in both lower endplate and vertebral body of the $L 4$ and upper endplate and vertebral body of the L5. The portion between the two white arrows is the transparent strip. The blue arrow indicates the normal cancellous bone manifestation of the vertebral body. The orange arrow indicates the "hardening"that occurs after a compressive fracture of the cancellous bone inside the vertebral body

mainly causes low back pain and only mild lower limb symptoms. For this kind of condition, OLIF can be used, and the clinical results are generally satisfactory. But for patients with concomitant conditions such as lumbar spinal stenosis or lumbar disc herniation, the lower limb symptoms may be more significant, therefore, and standalone OLIF cannot be used. The reason for using OLIF combined with pedicle screw fixation is that for osteoporosis patients, adding posterior internal fixation can reduce cage subsidence and increase the early fusion rate. Of course, the addition of posterior internal fixation will increase the economic burden on the patients. Therefore, for patients without osteoporosis or obesity, standalone OLIF is probably enough and should avoid damage to the back muscles and improves recovery, but additional studies are necessary to confirm those results. In addition, whether direct decompression could provide additional benefits should be examined.

Demineralized bone matrix (DBM) is a key factor in promoting fusion, and both groups received this growth factor, limiting the intergroup variability. In elderly 
patients with osteoporosis who received posterior pedicle screw fixation, the use of DBM increases the local stability and avoids compression fracture of the endplate caused by the cage, leading to a higher fusion rate. In this study, no allograft, autograft, or other bone substitute was used, and it should be examined in the future whether their use result in similar outcomes.

The present study has limitations. There trospective design introduces a degree of uncertainty due to missing and erroneous data. Especially, imaging examinations were performed routinely and the exact parameters were at the radiologists' discretion at the time of examination, possibly introducing some bias in the measurements. Second, the small sample size likely affects the power of the statistical analysis of the demographics and radiological parameters. Third, the follow-up was short because OLIF has been introduced only a short time ago. Finally, even if the surgeons share a common education and training and regularly assist each other with cases and have a long history of cooperation, the patients were from two hospitals, possibly introducing bias. The possibilty of proof lies within a future prospective study, preferably an RCT.

\section{Conclusion}

Standalone OLIF may achieve equivalent clinical and radiological outcomes compared to OLIF combined with fixation for spondylolisthesis. The rate of complication was similar between the two groups. Standalone OLIF does not invade the paraspinal muscle groups, possibly leading to better clinical effect and faster recovery, saving social and personal medical costs. Patients who are osteoporotic might be better undergoing combined rather than standalone OLIF.

\section{Abbreviations}

OLIF: Oblique lateral interbody fusion; VAS: Visual analog scale; ODI: Oswestry Disability Index; DH: Disc heights; FH: Foraminal height; FW: Foraminal width; DSD: Degenerative lumbar spine disease; LLIF: Lateral lumbar interbody fusion; ALIF: Anterior lumbar interbody fusion; AA: Abdominal aorta; PM: Psoas muscle; BMD: Bone mineral density; CT: Computed tomography

\section{Acknowledgements}

None.

\section{Authors' contributions}

$\mathrm{WH}, \mathrm{DH}, \mathrm{WT}$ and $\mathrm{XJY}$ carried out the studies, participated in collecting data and drafted the manuscript. JKW, WHW, YHX, and MML performed the statistical analysis and participated in its design. YQS and YGX helped to draft the manuscript. All authors read and approved the final manuscript.

\section{Funding}

This study was funded by Beijing Jishuitan Hospital "Nova Program" (Code: XKXX201808), Beijing Hospital Authority Youth Program (Code:QML 20190403), and Beijing Jishuitan Hospital" Medical and Engineering Intersection Project" (Code: YGQ-201924).

\section{Availability of data and materials}

The datasets used and/or analysed during the current study available from the corresponding author on reasonable request.

\section{Ethics approval and consent to participate}

The study was approved by the ethical committees of the Beijing Jishuitan Hospital (approval number: 201811-03) and the Shanghai Changzheng Hospital (approval number: 201812-01). The need for individual consent was waived by both committees because of the retrospective nature of the study.

Consent for publication

Not applicable.

\section{Competing interests}

The authors declare that they have no competing interests.

Received: 17 September 2019 Accepted: 9 March 2020

Published online: 23 March 2020

\section{References}

1. Ravindra VM, Senglaub SS, Rattani A, Dewan MC, Hartl R, Bisson E, et al. Degenerative lumbar spine disease: estimating global incidence and worldwide volume. Global Spine J. 2018:8:784-94. https://doi.org/10.1177/ 2192568218770769.

2. Rhee JM, Schaufele M, Abdu WA. Radiculopathy and the herniated lumbar disc. Controversies regarding pathophysiology and management. J Bone Joint Surg Am. 2006;88:2070-80.

3. Gregory DS, Seto CK, Wortley GC, Shugart CM. Acute lumbar disk pain: navigating evaluation and treatment choices. Am Fam Physician. 2008;78: $835-42$

4. Silvestre C, Mac-Thiong JM, Hilmi R, Roussouly P. Complications and morbidities of mini-open anterior retroperitoneal lumbar Interbody fusion: oblique lumbar Interbody fusion in 179 patients. Asian Spine J. 2012;6:8997. https://doi.org/10.4184/asj.2012.6.2.89.

5. Hynes R. Oblique lateral interbody fusion (OLIF) technique and complicationsin 457 levels L1 to S1. In: International society for the advancement of spinesurgery. Florida; 2014

6. Davis T, Hynes RA, Fung DA, Spann SW, MacMillan M, Kwon B, et al. Retroperitoneal oblique corridor to the L2-S1 intervertebral discs in the lateral position: an anatomic study. J Neurosurg Spine. 2014;21:785-93. https://doi.org/10.3171/2014.7.SPINE13564.

7. Zeng ZY, Xu ZW, He DW, Zhao X, Ma WH, Ni WF, et al. Complications and prevention strategies of oblique lateral Interbody fusion technique. Orthop Surg. 2018;10:98-106. https://doi.org/10.1111/os.12380.

8. Zhang JF. Clinical value of one-level oblique lateral interbody fusion in the treatment of degenerative lumbar disc diseases. ZhonghuaGuKeZaZhi. 2017; 37:80-8.

9. Pimenta L, Marchi L, Oliveira L, Coutinho E, Amaral R. A prospective, randomized, controlled trial comparing radiographic and clinical outcomes between stand-alone lateral interbody lumbar fusion with either silicate calcium phosphate or rh-BMP2. J Neurol Surg A Cent Eur Neurosurg. 2013; 74:343-50. https://doi.org/10.1055/s-0032-1333420.

10. Kwon YK, Jang JH, Lee CD, Lee $S H$. Fracture of the $L-4$ vertebral body after use of a stand-alone interbody fusion device in degenerative spondylolisthesis for anterior L3-4 fixation. J Neurosurg Spine. 2014;20:6536. https://doi.org/10.3171/2014.3.SPINE121018.

11. Mehren C, Mayer HM, Zandanell C, Siepe CJ, Korge A. The oblique anterolateral approach to the lumbar spine provides access to the lumbar spine with few early complications. Clin Orthop Relat Res. 2016;474:2020-7. https://doi.org/10.1007/s11999-016-4883-3.

12. Ohtori S, Orita S, Yamauchi K, Eguchi Y, Ochiai N, Kishida S, et al. Mini-open anterior retroperitoneal lumbar Interbody fusion: oblique lateral Interbody fusion for lumbar spinal degeneration disease. Yonsei Med J. 2015;56:10519. https://doi.org/10.3349/ymj.2015.56.4.1051.

13. Donnally IC, Varacallo M. Lumbar Degenerative Disk Disease. In: StatPearls: Treasure Island (FL); 2018.

14. Lim TH, Kwon H, Jeon $\mathrm{CH}$, Kim JG, Sokolowski M, Natarajan R, et al. Effect of endplate conditions and bone mineral density on the compressive strength of the graft-endplate interface in anterior cervical spine fusion. Spine (Phila Pa 1976). 2001;26:951-6.

15. Bridwell KH, Lenke LG, McEnery KW, Baldus C, Blanke K. Anterior fresh frozen structural allografts in the thoracic and lumbar spine. Do they work if combined with posterior fusion and instrumentation in adult patients with kyphosis or anterior column defects? Spine (Phila Pa 1976). 1995;20:1410-8. 
16. Fujibayashi S, Hynes RA, Otsuki B, Kimura H, Takemoto M, Matsuda S. Effect of indirect neural decompression through oblique lateral interbody fusion for degenerative lumbar disease. Spine (Phila Pa 1976). 2015;40:E175-82. https://doi.org/10.1097/BRS.0000000000000703.

17. Sato J, Ohtori S, Orita S, Yamauchi K, Eguchi Y, Ochiai N, et al. Radiographic evaluation of indirect decompression of mini-open anterior retroperitoneal lumbar interbody fusion: oblique lateral interbody fusion for degenerated lumbar spondylolisthesis. Eur Spine J. 2017;26:671-8. https://doi.org/10. 1007/s00586-015-4170-0.

18. Yang $Y$, Zhang L, Liu B, Pang M, Xie P, Chen Z, et al. Hidden and overall haemorrhage following minimally invasive and open transforaminal lumbar interbody fusion. J Orthop Traumatol. 2017;18:395-400. https://doi.org/10. 1007/s10195-017-0464-9.

19. Wang YP, An JL, Sun YP, Ding WY, Shen Y, Zhang W. Comparison of outcomes between minimally invasive transforaminal lumbar interbody fusion and traditional posterior lumbar intervertebral fusion in obese patients with lumbar disk prolapse. Ther Clin Risk Manag. 2017;13:87-94. https://doi.org/10.2147/TCRM.S117063.

20. Li H, Wang H, Zhu Y, Ding W, Wang Q. Incidence and risk factors of posterior cage migration following decompression and instrumented fusion for degenerative lumbar disorders. Medicine (Baltimore). 2017;96:e7804. https://doi.org/10.1097/MD.0000000000007804.

21. Lee JG, Lee SM, Kim SW, Shin H. Repeated migration of a fusion cage after posterior lumbar interbody fusion. Korean J Spine. 2013;10:25-7. https://doi. org/10.14245/kjs.2013.10.1.25.

22. Pan FM, Wang SJ, Yong ZY, Liu XM, Huang YF, Wu DS. Risk factors for cage retropulsion after lumbar interbody fusion surgery: series of cases and literature review. Int J Surg. 2016;30:56-62. https://doi.org/10.1016/j.jisu.2016.04.025.

23. Lee DY, Park YJ, Song SY, Jeong ST, Kim DH. Risk factors for posterior cage migration after lumbar Interbody fusion surgery. Asian Spine J. 2018;12:5968. https://doi.org/10.4184/asj.2018.12.1.59

24. Lin JF, lundusi R, Tarantino U. Intravertebral plate and cage system via lateral trajectory for lumbar interbody fusion-a novel combined device. Spine J. 2010;10:586.

25. Kim JS, Choi WS, Sung JH. 314. Minimally invasive oblique lateral interbody fusion for L4-5: clinical outcomes and perioperative complications. Neurosurgery. 2016;63:190-1

26. Mannion AF, Brox JI, Fairbank JC. Comparison of spinal fusion and nonoperative treatment in patients with chronic low back pain: long-term follow-up of three randomized controlled trials. Spine J. 2013;13:1438-48. https://doi.org/10.1016/j.spinee.2013.06.101.

\section{Publisher's Note}

Springer Nature remains neutral with regard to jurisdictional claims in published maps and institutional affiliations.

Ready to submit your research? Choose BMC and benefit from:

- fast, convenient online submission

- thorough peer review by experienced researchers in your field

- rapid publication on acceptance

- support for research data, including large and complex data types

- gold Open Access which fosters wider collaboration and increased citations

- maximum visibility for your research: over $100 \mathrm{M}$ website views per year

At $\mathrm{BMC}$, research is always in progress.

Learn more biomedcentral.com/submissions 